Conheci a Dra. Carla Evans em 2000, quando ao término da minha residência no Eastman Dental Center, Rochester, comecei a contatar vários departamentos sobre uma possivel proposta de emprego. Dra. Carla Evans é chefe do Departamento de Ortodontia da Universidade de Illinois desde 1994. Antes de Illinois, ela foi também chefe do Departamento em Harvard, onde estudou e permaneceu desde 1975. Desde sua chegada em Illinois, ela transformou o departamento de um programa com passado ilustre em um programa de presente e futuro brilhantes. Ela modernizou o currículo, equipou o Departamento com computadores e introduziu novas tecnologias, contratou novos professores tanto na área clínica quanto na área de ciências básicas. Hoje o programa voltou a ser considerado um dos 5 melhores dos EUA. Como educadora ela é conhecida como uma mulher de visão, como empreendedora é conhecida como uma mulher ativa e que consegue o que quer. No momento, o Departamento está às voltas numa campanha de renovação da clínica, que está sendo planejada somente com doações da associação dos ex-alunos e de empresas, já que o estado de Illinois, ao qual a Universidade pertence, decidiu não custear a reforma. Nem aqui verba é fácil de se conseguir! Como pesquisadora, seu currículo é imenso e já publicou mais de 120 artigos originais. Dra. Carla é co-editora do World Journal of Orthodontics e consultora de diversas revistas nacionais e internacionais de Ortodontia, Odontologia e anomalias craniofaciais. Já participou de inúmeros congressos e manteve consultório durante vários anos enquanto estava em Harvard e está sempre atualizada com as últimas práticas clínicas. Ela gosta de conhecer outros países e culturas, já esteve no Brasil, além da Ásia, Europa e outros países das Américas, e com essa mente aberta sempre há lugar para alunos estrangeiros no seu programa. Desde a minha chegada em Chicago, tenho aprendido com a sua convivência, sendo uma mulher avançada da qual estimo a sua experiência e idéias. É um prazer que ela tenha aceitado esse convite para podermos saber um pouco mais da sua opinião sobre os mais diversos assuntos da Ortodontia atual.

Adriana C. da Silveira

\section{Carla Evans}

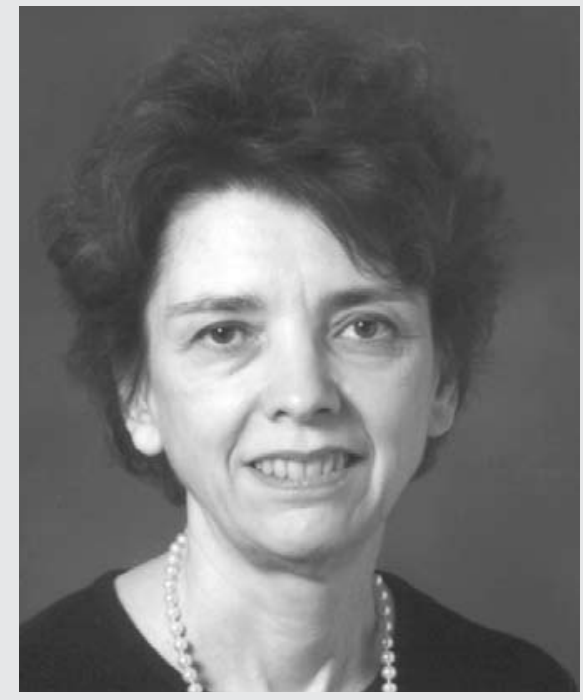

- Graduada em Odontologia pela University of Michigan;

- Certificado de Residência em Ortodontia pela Harvard University;

- Doutorado em Biologia Oral pela Harvard University;

- Professora e Chefe do Departamento de Ortodontia da University of Illinois em Chicago

- Co-Editora da Revista World Journal of Orthodontics.
1) Dra. Evans, como diretora e líder de um dos melhores Departamentos ortodônticos do mundo, quais são os ingredientes de seu sucesso, além de dedicação, habilidade e trabalho árduo? TM Graber

Meus segredos constituem bons genes, boa saúde, boa educação e bons conselhos. Herdei diversos talentos maravilhosos de meus pais. Devido às dificuldades econômicas, meus pais começaram a trabalhar ainda muito jovens e perderam as oportunidades disponíveis aos indivíduos que possuíam vantagens educacionais. Minha mãe, particularmente, estava determinada a oportunizar sucesso a seus filhos na escola e manteve esse propósito. Infelizmente, meu pai faleceu quando eu tinha 5 anos, porém naquela época eu já aprendera muitas coisas com ele sobre como solucionar problemas. Ingressei no programa de Ciência Física da Universidade de
Michigan e posteriormente decidi estudar Odontologia. Após a graduação na Escola de Odontologia da Universidade de Michigan, fui admitida nos programas de Harvard/Forsyth para obtenção do certificado de especialista em Ortodontia e do grau de Dra. em Ciências Médicas. Um bom conselho que recebi certa ocasião estava impresso em um cartão: "essas palavras abrirão muitas portas para você: puxe e empurre!”. Todo o talento no mundo não terá valor se o indivíduo não tentar.

2) Você enfrentou uma faculdade de Odontologia machista, chauvinista que dominava a educação odontológica quando iniciou. A que deve 0 seu sucesso e 0 de outras mulheres, visto que atualmente há mais mulheres em Odontologia e Ortodontia do que jamais houve? Algum conselho para o futuro? TM Graber 
Alguma vez sofreu discriminação como muIher em sua carreira? Adriana da Silveira

Eu era a única mulher na classe de Odontologia da Universidade de Michigan no outono de 1965. Haviam deixado claro para mim que mulheres não deviam estar em uma escola de Odontologia. No entanto, lá estava eu e muito feliz por ter ocupado um lugar na classe! O final dos anos de 1960 foi uma época turbulenta nos Estados Unidos com a liberação das mulheres no horizonte, marchas de protesto e os hippies ocupando as cidades universitárias. A Odontologia aceitou mudanças muito vagarosamente, e passaram-se muitos anos para que um número significativo de mulheres ocupasse um lugar em cada classe das escolas de Odontologia. Igual tratamento às estudantes do gênero feminino também se prolongou em Harvard. Em 1970, Coenraad F. A. Moorrees levou sua nova classe de Ortodontia para almoçar no Clube de Harvard na Avenida Massachusetts em Boston, como fazia todo ano. Ele observou que o Clube Harvard tinha acabado de abrir as portas para as mulheres e que eu tinha muita sorte de me permitirem almoçar lá. Aquele comentário realmente me aborreceu.

3) Atualmente, estamos vivendo em um mundo globalizado. Essa tendência chegou à Ortodontia por meio da World Federation of Orthodontists (WFO) que recentemente estabeleceu normas para um padrão mínimo na formação do especialista em todo o mundo. Em sua opinião, como deve ser a formação do especialista em Ortodontia e Ortopedia Facial em termos de currículo, carga horária mínima e duração? Roberto Lima

O último relato Erasmus sintetizado por Van der Linden ${ }^{1}$ teve um forte impacto em minhas visões sobre a educação ortodôntica. Um programa da especialidade ortodôntica deve constituir uma experiência em tempo integral com duração suficiente para que os alunos iniciem e finalizem o tratamento de um número substancial de pacientes.
Concordo com Van der Linden no sentido de que um programa de Ortodontia deve abranger disciplinas médicas e biológicas em geral, assim como a discussão de assuntos ortodônticos básicos. A inter-relação entre disciplinas clínicas, tais como a Cirurgia Bucal e Craniofacial, a Periodontia, a Odontologia Restauradora e a Odontologia Pediátrica, é muito importante. As oportunidades didáticas, laboratoriais e de pesquisa, com o apoio estatístico, do computador e da biblioteca, devem ser fornecidas. Uma experiência de pesquisa constitui uma preparação satisfatória para o futuro, porque o futuro é desconhecido. Ao longo da vida, o ortodontista deve questionar, avaliar as evidências e tirar conclusões. Tipicamente, as disciplinas clínicas são ensinadas por meio da demonstração, não por exploração.

Os exames de certificação do Board devem estar disponíveis para os ortodontistas jovens no final de seus programas da especialidade. Sou bastante favorável no sentido de se seguir o modelo médico no que se refere à certificação e às exigências do Board para o aprendizado por toda a vida. Nos Estados Unidos, os padrões de credulidade exigem que um diretor de programa possua um certificado do Board. Entretanto, é baixo o número de ortodontistas orientados do ponto de vista acadêmico com certificação do Board. Anteriormente, muitos acadêmicos altamente qualificados acreditavam que o certificado do Board era inatingível devido à sua mobilidade profissional, à ausência de pacientes apropriados nas práticas da faculdade odontológica e à falta de controle sobre seus horários de trabalho. As novas diretrizes devem auxiliar o suprimento de educadores ortodônticos.

4) Com a transformação da documentação existente em digital, o próximo passo será a combinação de ambas para criar um registro digital integrado da morfologia dentofacial do paciente. Qual o impacto dessa tecnologia no diagnóstico e plano de tratamento? Roberto Lima 
A carência de padrões adequados na informática voltada à Odontologia afeta demasiadamente os ortodontistas. Por exemplo, estes podem comprar pacotes de software com formatos proprietários que se tornam altamente inconvenientes quando a empresa vai à falência, as prioridades do médico mudam ou as informações precisam ser removidas para outras aplicações. Além disso, torna-se muito difícil transferir as informações de um paciente aos colegas que possuem um software diferente. O desenvolvimento de padrões é a chave para facilitar as comunicações digitais mundiais relacionadas à Ortodontia. $\mathrm{O}$ verdadeiro potencial de registros digitais não será alcançado até que os clínicos possam trocar informações livremente. Estamos apenas iniciando a utilização da tecnologia digital.

O Congresso dos Estados Unidos tornou obrigatório que os registros eletrônicos do paciente fossem transferiveis e criou o ONCHIT - Office of the National Coordinator for Health Information Technology (Escritório do Coordenador Nacional para a Tecnologia de Informação em Saúde) (http:www.os.dhhs.gov/healthit). Sob a direção do ONCHIT e do American National Standards Institute (ANSI) (Instituto Americano de Padrões Nacionais), painéis estão sendo formados para acelerar a interoperabilidade entre as tecnologias de informação no cuidado com a saúde. $\mathrm{O}$ website do ANSI apresenta informações detalhadas sobre os esforços que envolvem as agências cooperativas, as organizações, as empresas e os consultores (http:/www.ansi.org/standards_activities/standards_boards_panels/overview.aspx?menuid=3).

Autorizada pelo ANSI para o desenvolvimento de padrões, a American Dental Association (ADA) (Associação Americana de Odontologia) patrocina diversos comitês padronizadores que lidam com produtos e materiais odontológicos, assim como a informática odontológica. Inseridos no Standards Comittee on Dental Informatics (SCDI) (Comitê de Padronização da Informática Odontológica) da ADA estão diversos grupos de trabalho que investigam assuntos relacionados à Ortodontia, tais como os padrões para as radiografias $2 \mathrm{D}$ e $3 \mathrm{D}$, as fotografias digitais, as prescrições laboratoriais e a disseminação eletrônica dos registros do paciente. Recentemente, O SCDI da ADA formou o Working Group 11.6 (Grupo de Trabalho 11.6) para lidar com a integração de padrões ortodônticos e os componentes ortodônticos dos registros eletrônicos em saúde. O Working Group 11.6 possui atividades em duas direções: 1) dados de imagem e geometria (extensões ortodônticas de DICOM incluindo sobreposições, pontos, pontos de referência, anotações, etc., com foco no armazenamento, na interpretação, na apresentação, no compartilhamento, no registro e no exame de tais informações), e 2) dados textuais e numéricos (demográficos, diagnósticos, outros elementos de informação, planos de tratamento e resultados). Incluso nos grupos interessados no progresso do Working Group 11.6 encontra-se o Conselho Americano de Ortodontia, visto que tenta desenvolver novos exames baseados nos registros digitais do paciente.

\section{5) Para que qualquer informação seja con- fiável, é necessário estar fundamentada em princípios bem estabelecidos. Novos dispo- sitivos e inovações mágicas aparecem hoje e desaparecem amanhã. Como a comunidade científica poderia contribuir para resolver esse problema? Roberto Lima}

Os produtos do consumo são avaliados por laboratórios de teste independentes, tais como o Consumers Union/Consumer Reports e o Underwriters Laboratory, Inc. Não temos nada semelhante na Ortodontia. Seria muito útil se na prática os ortodontistas tivessem acesso ao trabalho de laboratórios independentes conceituados para obter relatos que lidam com o teste de corrosão, os defeitos dos produtos, etc. Talvez a Ortodontia organizada pudesse impulsionar essa idéia.

\footnotetext{
6) Com base em seus trabalhos sobre percepção da protrusão labial por leigos, como tem procedido ao apresentar o plano de
} 
tratamento a seus pacientes? Tem utilizado rotineiramente programas de simulação computadorizada? Adilson Luiz Ramos

O programa de simulação descrito em meus artigos deve ser considerado como uma entrevista computadorizada ou um teste de preferência, e não uma predição dos resultados do tratamento. O computador é utilizado para facilitar a comunicação do paciente com o ortodontista: não há intenção de apresentar as opções para o paciente. Os resultados científicos recentes sobre a percepção da atratividade facial, juntamente com os avanços tecnológicos na imagem computadorizada, tornam possível mensurar as características faciais que possam estar associadas com julgamentos específicos da aparência facial. Esses novos métodos podem ser utilizados para produzir normas psicométricas de atratividade facial, que podem, potencialmente, suplementar as normas convencionais da população ou as médias utilizadas atualmente no plano de tratamento ortodôntico. Espero que a consideração sobre as normas psicométricas aprimore a comunicação ortodontista-paciente e leve a uma maior satisfação do paciente no final do tratamento ortodôntico. O uso do programa de simulação para determinar as preferências do paciente é objetivo e pode, inclusive, detectar expectativas não realistas.

7) Em dois estudos publicados ${ }^{2,3}$ no AJODO 2003 e 2004 em que a Sra. participou, foi avaliado o papel dos restos epiteliais de Malassez, bem como da integrina (receptor) alfav-beta-3 na movimentação ortodôntica. Quais são as novidades nesta área, e o que podemos vislumbrar para o futuro, em termos ortodônticos clínicos? Adilson Luiz Ramos

A movimentação dentária constitui um fenômeno biológico, porém não sabemos muito sobre como alterar a resposta biológica. Para controlar a reabsorção radicular, aprimorar a ancoragem, acelerar o índice de movimentação dentária e eliminar a recidiva torna-se imprescindivel estudar as atividades celulares no periodonto, tais como os res- tos epiteliais produzindo colagenase, osteoclastos e odontoclastos. Visto que os tecidos não sabem que tipo de braquete está sobre o dente, devemos determinar quais os sinais que eles reconhecem. O futuro deve incluir uma duração de tratamento mais curta com menos efeitos colaterais e mais resultados estáveis. Alguns experimentos bastante interessantes estão sendo realizados atualmente para testar o potencial de um hormônio, a relaxina, como uma forma de reduzir a recidiva.

\section{Adilson Luiz Ramos}

- Editor da Revista Dental Press de Ortodontia e Ortopedia Facial.

- Mestre em Ortodontia pela FOB-USP - Bauru.

- Doutor em Ortodontia pela UNESP - Araraquara.

- Professor de Ortodontia do Departamento de Odontologia

- UEM - Maringá.

Adriana C. da Silveira

- Mestrado e Doutorado em Biologia Craniofacial da University of Florida.

- Certificado de Residência em Ortodontia do Eastman Dental Center/ University of Rochester.

- Professora Assistente dos Departamentos de Ortodontia e Cirurgia da University of Illinois in Chicago.

- Chefe de Ortodontia do Centro Craniofacial da University of Illinois in Chicago.

- Diplomada pelo American Board of Orthodontics.

\section{Roberto Mario Amaral Lima Filho}

- Mestre em Ortodontia pela Universidade Federal do Rio de Janeiro.

- Diplomado pelo Board Brasileiro de Ortodontia.

- Diplomate of the American Board of Orthodontics.

- Membro da Edward H. Angle Society of Orthodontists.

\section{T. M. Graber}

- DMD, MSD, PhD, DSc (Hon).

- ScD (Hon), MD (Hon), Dr. Dent (Hon), Odont. Dr, (HC), Dr. Dent. (Hon), FRCS.

- Professor da University of Illinois in Chicago.

- Editor Chefe do World Journal of Orthodontics.

1. VAN DER LINDEN, F. P. Three years postgraduate programme in Orthodontics: the final report of the Erasmus Project. Eur $\mathbf{J}$ Orthod, Oxford, v. 14, no. 2, p. 85-94, Apr. 1992.

2. TALIC, N. F.; EVANS, C. A.; DANIEL, J. C.; ZAKI, A. E. Proliferation of epithelial rests of Malassez during experimental tooth movement. Am J Orthod Dentofacial Orthop, St. Louis, v. 123, no. 5, p. 527-533, May 2003.

3. TALIC, N. F.; EVANS, C. A.; DANIEL, J. C.; GEORGE, A.; ZAKI, A. $M$. Immunohistochemical localization of alpha-v-beta-3 integrin receptor during experimental tooth movement. Am J Orthod Dentofacial Orthop, St. Louis, v. 125, no. 2, p. 178-84, Feb. 2004.

Tradução: Rosemary Piancó Gulla 